\title{
La necesidad de una ciudadanía cada vez más crítica en Costa Rica para el fortalecimiento de su democracia
}

\section{The need for increasingly critical citizens in Costa Rica to strengthen democracy}

Yors Guillermo Solís Vargas

Ministerio de Educación Pública, Costa Rica

yors.solis.vargas@mep.go.cr

Recibido: 20/05/2018 • Aceptado: 01/05/2019

\section{RESUMEN}

El siguiente artículo pretende analizar de manera crítica el papel del ciudadano costarricense ante la democracia actual. Hoy, se puede decir que el panorama político del país ha estado alterado por la corrupción y la influencia del fenómeno conocido como posverdad, por lo que una ciudadanía cada vez más crítica para que pueda elegir con un proceder más informado y racional a sus gobernantes es una apuesta necesaria. ¿Cómo lograr esto? Desde el punto de vista del autor, a través de constantes observaciones a la política de ramo desde todos los ámbitos de la sociedad y, por otro, y más importante, con buena formación crítica desde tempranas edades. Para este análisis se van a revisar y discutir algunos textos periodísticos, jurídicos, educativos y filosóficos sobre el tema de la posverdad, la democracia y la educación costarricense. Al final, se concluirá con una reflexión en relación con el título de este escrito.

Palabras clave: Política, educación, gobierno, Costa Rica. 


\begin{abstract}
This article is intended to critically analyze the role played by Costa Rican citizens in determining the current state of democracy in the country. The country's political panorama has currently been disrupted by corruption and the phenomenon known as post-truth. It is therefore imperative to have critical citizens so that they can elect leaders on a more informed and rational basis. How can this be achieved? From the author's perspective, through constant observation of the actual state of politics from every area of society; and more importantly, through a sound critical education beginning at an early age. Journalistic, legal, educational and philosophical texts about post-truth, democracy and Costa Rican education will be reviewed and discussed in this analysis, which concludes with a reflection on topics related to the title of this document.
\end{abstract}

Keywords: Politics, education, government, Costa Rica.

\title{
INTRODUCCIÓN
}

El En vista de los acontecimientos recientes en relación con la política de Costa Rica, ¿se puede decir que es un país libre de corrupción, con una democracia y una educación racional y crítica? Si no es así, ¿cuál o cuáles pueden ser las posibles soluciones ante esta problemática? Asimismo, ¿está Costa Rica exenta de la influencia de los actuales fenómenos políticos internacionales, particularmente del conocido como posverdad? Estas son las principales interrogantes que el autor pretende analizar en las diferentes divisiones de este escrito y ante las cuales se plantea la hipótesis central de que una educación, cuanto más crítica sea, puede incidir de forma positiva en el fortalecimiento de la democracia de Costa Rica.

Además de los últimos sucesos de corrupción política y económica ocurridos en Costa Rica, esta última campaña electoral mostró de una manera más clara lo que se conoce como el fenómeno de la posverdad, término que proviene del inglés post-truth. Como lo indica el Diccionario de Oxford (Oxford dictionary online, 2019), denota o se relaciona con circunstancias en las que los hechos objetivos influyen menos en la formación de la opinión pública que las apelaciones a la emoción y a las creencias personales. Este fenómeno, aunado al hecho de que Costa Rica ha estado bajo una creciente ola de corrupción, es lo que motiva al 
autor para justificar y proponer una mayor atención crítica a la política y a la educación de este país.

El término posverdad, como aquí se va a concebir, lo utiliza por primera vez Ralph Keyes en su libro The Post-Truth Era. Dishonesty and Deception in Contemporary Life (2004). En este texto, se puede determinar que, además de la mentira política como medio para lograr hacer un llamado a la mayoría y convencer a la población sobre algún asunto político, también los insultos y las calumnias en redes sociales y el show televisivo representan elementos que componen este fenómeno que, en los últimos años, ha ido en detrimento de la democracia .

Este nuevo fenómeno, mundialmente popular a partir de las elecciones presidenciales de Estados Unidos y el Brexit en Gran Bretaña en 2016, se hace evidente también en Latinoamérica en países como México, Argentina, Costa Rica, entre otros. En Costa Rica se evidenció muy claramente durante las elecciones a diputados y presidente 2018, y los resultados representan un llamado de atención para no seguir cometiendo los mismos fallos en los que han incurrido ciudadanos de otras naciones a raíz de esta nueva forma de populismo.

Durante las elecciones presidenciales de Estados Unidos y el Brexit, las mentiras por medio de entrevistas, redes sociales, propaganda política, etc., llegan a ocupar un lugar privilegiado frente a los hechos objetivos a la hora de formar la opinión de los votantes. Para demostrar esto, se van a citar varios ejemplos de este fenómeno político.

Uno es la afirmación que hizo el ahora presidente estadounidense Donald Trump en distintos medios televisivos durante la campaña electoral en 2016. Este sostenía que Barack Obama era el fundador de ISIS y Hillary Clinton (su oponente en la campaña por la presidencia) su cofundadora (McKirdy, 2016). Sin embargo, tiempo después en redes sociales y entrevistas Trump afirmó que había sido sarcástico y que no había querido decir eso (Kopan, 2016).

1 Lo cual conlleva a pensar en otro fenómeno más profundo que también se le ha prefijado con el post: la posdemocracia (o la pérdida de la democracia entendida idealmente como la mejor forma de gobierno). También, el término está asociado a otros como pospolítica o fin de la política, contrademocracia, impolítica, modernidad líquida, valores posmateriales, etc. 
Otro ejemplo fueron las consignas que los partidarios del Brexit utilizaban durante la campaña previa al referéndum. Entre las mentiras que usaban para ganar seguidores estaba una que consistía en la idea errónea de que mantenerse en la Unión Europea (UE) tiene un costo de 350 millones de libras semanales que serían reintegradas al país si se tomaba la decisión de abandonar la UE; sin embargo, un día después de haber ganado el referéndum, uno de sus promotores (Nigel Farage) confesó en un medio televisivo que fue un error prometer al país 350 millones de libras semanales (Soler, 2016). Estos hechos dejan en evidencia que las mentiras y la apelación a las emociones del colectivo, durante unas elecciones populares, está ganando la opinión de ciudadanos que parece que ya no les interesan los hechos objetivos para tomar decisiones.

Así también en Latinoamérica se evidencia la influencia de este fenómeno político. Un ejemplo de esto fue el anuncio publicitario del presidente mexicano Enrique Peña Nieto en el cual afirmó que “...con la reforma energética, no habría más incrementos en los precios de las gasolinas, gas y energía eléctrica, hoy la realidad lo ha rebasado" (Jiménez, 2017). Esta nueva forma de mentira política, aunado al hecho de que en Costa Rica la corrupción ha permeado todos los poderes de la República (Cuevas, 2017), hace cada vez más urgente la necesidad de, por un lado, un constante y profundo análisis de la política y, por otro, de la apremiante formación crítica de los ciudadanos desde tempranas edades. En las siguientes secciones se pretende analizar, por medio de la revisión crítica de documentos periodísticos, jurídicos, educativos y filosóficos, la situación actual de la democracia costarricense.

\section{La corrupción política costarricense}

La corrupción política en Costa Rica no es tema reciente; desde los juicios, conocidos popularmente como Caja-Fischel (2009) e ICE-Alcatel (20102016), a ex presidentes de la república, se abrió un portillo ante la posibilidad de juzgar los actos deshonestos que los gobernantes cometan contra el pueblo. Previo a estas fechas es muy probable que haya más ex presidentes involucrados en actos de corrupción; sin embargo, denuncias y medidas judiciales tan sólidas y evidentes como estas no tienen precedentes (Cambronero, 2009; Núñez, 2016). 
Después de estos hechos, el tema de la corrupción política no ha decrecido. Más bien, se han ventilado casos de corrupción que no solo tocan al poder ejecutivo, sino también a los demás poderes de la República. Ejemplo de esto es el caso del "Cementazo", en 2017, el cual representa una evidencia actual del desorden organizativo del Estado y de la cada vez más creciente corrupción que afecta a los tres poderes de Costa Rica (Sancho, 2017). Ante esta situación se pueden señalar culpables, pero más allá de estos señalamientos, también los ciudadanos son, hasta cierto punto, cómplices de estos delitos, ya que son estos los que eligen a quienes los gobiernan.

Se podría afirmar que los ciudadanos son víctimas de los gobernantes, pues en principio estos se muestran honestos y luego, cuando obtienen puestos políticos, dejan de serlo. Además, la educación, tema dominado por los gobiernos, en muchos casos no tiene como principal objetivo formar ciudadanos críticos para que estos puedan valorar racionalmente por quién votar. No obstante, estos argumentos no son pruebas concluyentes de que los ciudadanos costarricenses no puedan hacerle frente a los gobernantes deshonestos por medio de un voto más informado y de la libre expresión -bien argumentada-. La educación de este país es una de las mejores de la región y la Constitución Política de Costa Rica (1949) permite la expresión de pensamientos (artículo 29); además, al haber firmado la Convención Americana sobre Derechos Humanos (1969), el derecho a la libertad de pensamiento y de expresión (artículo 13) cuenta con más peso legal en el país, lo cual no deja excusas a los ciudadanos para que, aunque sea por formación personal, opinen de una manera más crítica a la hora de ejercer la democracia.

Ante la situación política actual, ¿qué solución puede haber? Una educación más crítica en todas las materias de la enseñanza pública costarricense, pero principalmente en la materia de cívica ${ }^{2}$, ya que este enfoque representa una de las maneras más profundas de hacerle frente a la corrupción política. Formando estudiantes críticos y cívicamente activos con respecto a su vida en sociedad, se puede atacar la demagogia, la retórica

2 La cual solo está de manera independiente en secundaria, ya que en primaria es parte de la materia de estudios sociales. 
política, el populismo, etc., ${ }^{3}$ que algunos gobernantes emplean con el fin de llegar, a toda costa, a dirigir el país.

Formación Crítica se va a entender como la capacidad de análisis evaluativo (según las capacidades de cada grupo de estudiantes), en este caso, de la política costarricense, por la cual se podría lograr un ciudadano más racional a la hora de ejercer el voto y su ciudadanía. ¿Cómo lograr esto? Por medio de estrategias educativas como diálogos, ensayos, debates, estudio de cuadros comparativos de distintas formas de gobernar; además, análisis discursivos, estadísticos, sociales, lógicos, éticos, etc. ${ }^{4}$

Así también, en la materia de cívica, además de formar críticamente, se debería promover el civismo "activo", el cual se va a entender como un civismo de participación, de compromiso, de acción, tal y como lo anota Ramoneda:

Junto a este civismo pasivo cabría uno activo: civismo de participación, de compromiso, de acción. Hacer de la cosa pública algo que realmente nos concierna a todos. Pero eso tiene un nombre: democracia. Y es curioso que los que proclaman el civismo como virtud son con frecuencia los que más han hecho para que la democracia se fuera desvaneciendo y la participación ciudadana se fuera reduciendo a pagar impuestos e ir una vez cada cuatro años a votar. El civismo es la doctrina adecuada a la apoteosis del ciudadano Nif [Número de Identificación Fiscal para españoles], el hombre de las tres "c", porque lo único que se le exige -y se le reconoce- es competir, consumir, contribuir (Ramoneda, 2003).

\section{La posverdad en Costa Rica}

Durante las últimas elecciones políticas en Costa Rica se evidenció, más enérgicamente que siempre, una nueva tendencia en la propaganda que está siendo casi crucial en la elección de los gobernantes de Costa Rica. Se trata de una especie de nuevo populismo o de mentira política conocido como posverdad.

3 Así como a la injusticia social, la discriminación de cualquier tipo, el respeto a la naturaleza, etc., etc.

4 La formación en estos últimos temas podría representar un cambio fundamental en los futuros adultos a la hora de ejercer el voto, pero desgraciadamente no hay en el país una tradición en la enseñanza de la lógica, de la ética o del pensamiento crítico. 
En Costa Rica este fenómeno se evidenció cuando el candidato del partido Restauración Nacional (que estaba muy abajo en las encuestas) empezó a valerse de la orden de acatamiento obligatorio de la Corte Interamericana de Derechos Humanos, de legalizar el matrimonio igualitario en Costa Rica, para empezar a apelar a las emociones y sentimientos de la moral tradicional y las creencias religiosas comunes del país y mostrarlas como lo verdadero y por las cuales se debería de votar o no por un candidato (Romero, 2018). Una de las afirmaciones más populares del candidato de este partido fue la de "salirse" de la Corte Interamericana de Derechos Humanos, ya que, según este, el matrimonio igualitario va en contra de las tradiciones morales y creencias religiosas del país. Sin embargo, poco a poco durante la campaña, esta aseveración se fue matizando hasta que en algún momento el mismo candidato llegó a decir en medios de prensa que no sería una buena decisión salirse de esta Corte (Madrigal, 2018), lo cual deja en evidencia que mentir y apelar a las emociones y creencias del pueblo para lograr apoyo electoral no es un fenómeno que solo está ocurriendo en otros países.

Lo objetivo y lo racional durante estas elecciones pasaron a un segundo plano y, debido a esta nueva forma de populismo, quedó demostrado que hubo gran parte de la población que no presentó interés en el debate argumentado, la buena formación de los candidatos o la investigación crítica de las propuestas políticas de los diferentes aspirantes. Simplemente muchos se dejaron llevar por afirmaciones como las del candidato de Restauración Nacional para elegir por quien votar.

Nun afirma que,

...en todas partes han perdido autoridad (a menudo por buenos motivos) los juicios de los expertos y de los periodistas, tradicionalmente encargados de discriminar entre verdad y mentira. Perón decía: "Alpargatas, sí; libros, no"; Trump declara: "Amo a la gente poco educada", y Beppe Grillo se alegra porque millones de personas ya no leen sus diarios ni miran su televisión. Cunde el antiintelectualismo y son legión los sabios y los entendidos que deben asumir su propia responsabilidad por este desenlace. Después de todo, los tecnócratas y los populistas tienen algo en común y es su aversión al debate: unos, porque poseen la única solución racional para cada problema; y los otros, porque sólo ellos 
expresan la voz del pueblo. En esto estamos y de ahí que resulte necesario y urgente tomar conciencia de las razones de fondo que han llevado a la emergencia del término posverdad. Indica a su modo que se viene cerrando una época y sería grave ignorarlo, por poco que nos gusten las personas como Trump (Nun, 2017).

Por lo anterior, se hace más evidente la necesidad de una mejor educación en el sentido crítico. Pero no una educación entendida en sí misma, centrada en sí misma, o una que se interese más por la formación técnica que por otros aspectos. Más bien es necesaria cada vez más una educación crítica que supere la idea de la formación cognoscitiva y técnica sin más. Es decir, una que también dé cuenta de aspectos éticos, estéticos, cívicos y políticos de la sociedad, ya que nada se logra si se tienen buenos profesionales, pero carentes de estos aspectos.

Ante esto, el Ministerio de Educación Pública (MEP) saliente propuso, en la nueva Política Educativa (2016), esfuerzos para lograr una nueva ciudadanía que esté mejor preparada en el sentido crítico-social, objetivo que no estaba tan claro en la anterior política educativa de 1994. Sin embargo, solo con el tiempo se podrá evidenciar si esta nueva política se va a llegar a concretar y represente una mejor forma de preparar al ciudadano ante tendencias propagandísticas poco racionales.

La educación centrada en la persona estudiante y su proceso de aprendizaje: El sistema educativo se orientará a la conformación de un nuevo sujeto social, capaz de trascender el individualismo, con el fin de asegurar una ciudadanía crítica, activa y propositiva ante sus propios desafíos, aprovechando las oportunidades que la sociedad le ofrece (MEP, 2016).

Es clara la posición político-educativa del MEP con respecto a lo que se quiere con la enseñanza nacional, ahora solo queda estar vigilante para que esta pretensión se cumpla a cabalidad y, efectivamente, la formación de la ciudadanía desde esta intención política sea cada vez mejor.

\section{La democracia costarricense}

Sócrates afirmaba, en el libro VI de La república (Platón, 1988) que los gobernantes deben ser personas preparadas en política y estos deben ser 
elegidos por ciudadanos racionales, pues si no es así, sería como darle el timón de un barco a una persona fuerte, pero corta de vista, habiendo un experto en conocimientos náuticos con todos sus sentidos en perfecto estado.

Es importante notar el valor que cobra en la filosofía socrática el conocimiento moral por cuanto se identifica con la conducta moral. Su misión de moralizador le lleva a criticar los fallos del Gobierno, la incompetencia y falta de honradez política sin que ello signifique mentalidad antidemocrática. En su empeño en moralizar al individuo y la sociedad es verosímil que propusiera que el mando debía otorgarse a los «mejores», que — de acuerdo con su teoría- eran los más «sabios»; «los que conocían la justicia» (Muñoz, 1977, p. 45).

Platón abogaba por un gobierno de los mejores, una aristocracia. Dejaba de lado a muchos de los pobladores que, algunos incluso, no eran considerados ciudadanos. Hoy la democracia en Costa Rica solo está limitada por la edad; es decir, solo podrán votar ciudadanos mayores de 18 años, ya que desde 2016 está en vigencia la ley n. ${ }^{\circ} 9379$, "Ley para la promoción de la autonomía personal de las personas con discapacidad", la cual elimina la exclusión total del voto por algún tipo de discapacidad (Asamblea Legislativa, 2016). Por lo que, ante un panorama así, la formación educativa de todo costarricense debe ser muy completa y, a juicio del autor, muy crítica. Pues no se trata de que solo una parte de la población sea la encargada de gobernar, sino que se trata de todo un pueblo que con su voto principalmente, está siendo responsable de las riendas del país. Así que, un voto informado, crítico y bien analizado por parte de cada ciudadano es lo que necesita tener la República para que de verdad no sean solo unos pocos los que eligen a los mejores, sino todos desde una participación activa, responsable y racional.

Pero, ¿qué pasaría si los mejores posibles gobernantes no están como postulantes para gobernar el país? Si dentro del paquete de candidatos todos son personas deshonestas, ¿qué pasa con la democracia representativa que es un derecho y un deber de todo ciudadano costarricense?

Las leyes establecen que existe el derecho a elegir, pero si no hay candidatos idóneos, entonces ¿hay que votar solo por el mero hecho de votar y así cumplir con el deber? Parece ser que hay aquí una paradoja: según 
el ideal del sistema político conocido como democracia representativa, el pueblo tiene el deber de elegir al gobernante más apto, pero qué pasa si no hay candidatos aptos a gobernante, como es obligatorio votar para cumplir con lo que dice la ley y la democracia, ¿se debe elegir a alguien aunque ese alguien no sea el más apto?

Parece ser que lo importante es el deber de votar y no la elección correcta de gobernantes. De este deber se valen muchos "dirigentes" mal intencionados para que se ejerza el voto y así se legitime un mal gobierno y se haga pensar a la sociedad que ejerció su derecho a votar (y que si el gobernante falla es culpa del pueblo por elegirlo).

Esta situación es peor si además de que no hay candidatos aptos para gobernar, tampoco hay votantes aptos que elijan, entonces se llega al punto de que cualquier ciudadano mal intencionado quiera y pueda llegar a ser, aunque por medios corruptos (como lo es la demagogia, la retórica, la propaganda engañosa, el tráfico de influencias, el populismo, etc.), gobernante del país.

¿Qué solución puede haber? En cuanto a que la mayoría de los ciudadanos quieran participar en política es una cuestión que va ligada a la formación en civismo activo, lo cual involucra de nuevo a la educación; $y$, en cuanto al apoyo de las mayorías hacia candidatos aptos, depende, igualmente, de un país educado en política y de la forma justa e igualitaria de hacer propaganda que les permita el Tribunal Supremo de Elecciones. No es la intención del autor reducir ingenuamente, la solución de estas problemáticas al hecho de educar con más criticidad, ya que hay otras soluciones que pueden ser muy atinentes ante este panorama, como pueden ser un sistema de justicia y unas leyes más estrictas y justas, pero para todo esto, el autor no encuentra una medida más fundamental, profunda y perdurable que una educación integral de calidad centrada principalmente, en la formación crítica de sus ciudadanos desde tempranas edades.

Es común que la contienda entre candidatos costarricenses a la presidencia dependa del partido político, del apoyo de empresarios, de la capacidad económica que se tenga para hacer propaganda o del manejo populista que se haga. Esto último es un caso bien evidenciado en las elecciones a diputados y presidente del año 2018; el partido Restauración Nacional se valió de la orden de acatamiento obligatorio de la Corte 
Interamericana de Derechos Humanos (legalizar el matrimonio igualitario en Costa Rica) para hacer propaganda política y lograr con esto un fuerte apoyo de la población.

En Costa Rica, parece ser que la propaganda es el medio de formación política de muchos ciudadanos para elegir a sus gobernantes. La mayoría se prepara para elegir presidente por medio de debates y publicidad cada cuatro años. Entonces, no importa si el candidato es una persona deshonesta o una persona poco capacitada, lo importante es cómo este convence a la población para que vote por él; en especial si se cuenta con el apoyo de un partido político tradicional, grandes donaciones de dinero para la campaña política o del buen manejo del populismo.

¿Qué solución puede haber ante esto? Además de una mejor formación crítica de la población, también sería necesaria una propaganda más justa e igualitaria entre los diferentes partidos políticos. Un mayor control de la publicidad para que no sea el dinero lo que marque la ventaja por uno $\mathrm{u}$ otro candidato, y promover debates o espacios igualitarios en medios escritos y televisivos en donde haya las mismas oportunidades para hacer publicidad política entre los diferentes candidatos. Con esto, se podría eliminar la brecha que existe entre algunos partidos con respecto a la capacidad propagandística que tiene cada candidato y así lo que marque la diferencia sea la capacidad racional (del partido y del candidato) para enfrentarse a debates, análisis, cuestionamientos, entre otros. Entonces no va a ser la propaganda y la publicidad lo que va ganarse la opinión de un pueblo (como es la costumbre en Costa Rica), sino la capacidad racional de un aspirante y su partido a la hora de pretender el gobierno del país en una contienda justa.

La democracia no es tan sencilla como simplemente ir y elegir a alguien para que represente al pueblo. De ahí la necesidad de acentuar y apostar por una educación más crítica y atinente al contexto socio-político para que las nuevas generaciones, en el futuro, participen activamente no solo como candidatos aptos sino también como votantes críticos. Ciudadanos justos, honrados, comprometidos con el país y con ansias de informarse constantemente para ejercer el voto cuando haya que hacerlo.

Años atrás, parecía intencional el hecho de que no se eduque al pueblo desde una pedagogía crítica en temas como análisis lógico, ético, político, 
etc., de la realidad nacional. Temas que solo se estudian en algunas universidades serias del país, pero que no se estudian formal, programada, independiente y sistemáticamente durante la educación general básica ni diversificada. Por lo que los estudiantes, cuando salían de la educación media, traían consigo una serie de desfases, prejuicios, vacíos cognoscitivos en torno a muchos temas de realidad nacional, como el tema de la política. Por otro lado, cuando tienen (si la tienen) la fortuna de llegar a cursar estudios en alguna universidad seria sobre alguno de los temas antes mencionados, ya vienen con un desfase en el tema político que les impide conectar conocimientos nuevos, ante lo cual se generan distintos escenarios cognoscitivos como mal interpretar (el socialismo), radicalizar (llegar a postular un anarquismo), rechazar sin argumentos (el comunismo) o dogmatizar algunas corrientes políticas (como es el caso del neoliberalismo).

Sin embargo, el panorama político-educativo ha cambiado. Hoy son evidentes los esfuerzos, desde el MEP, por formar ciudadanos críticos; pero esto apenas está iniciando y depende también de que los ciudadanos más estudiosos mantengan un constante análisis crítico de la realidad social y política para que poco a poco esta población sea más racional y más ética.

Existen herramientas para educar el criterio político de una persona, como por ejemplo la formación en lógica, en ética, en cívica (entendida no como civismo pasivo o descriptivo) entre otras. EI MEP implementó, en pasadas administraciones, programas o planes -como el proyecto Ética, Estética y Ciudadanía (2009a), los programas de Educación Cívica de secundaria (2009b), la integración de la enseñanza de la lógica en el Programa de Estudio de Español para el III Ciclo y Educación Diversificada (2009c), el programa de Estudios sociales y Cívica de primaria (2013), entre otros- que pretendieron formar a los estudiantes para que sean mejores ciudadanos. Desafortunadamente, cuando se plantearon estos proyectos, algunos se dejaron a cargo de profesionales no expertos en la materia ${ }^{5}$, se formularon sin diagnósticos previos y debilidades que a mediano plazo ya empezaron a fracasar -como se indica en el informe final presentado por el Centro de Recursos de Evaluación del Programa de Desarrollo de las Naciones Unidas (PNUD) sobre el proyecto de Ética, estética y ciudadanía del Ministerio de Educación Pública (Sans, Jenkins y Elizondo, 2009)- o se evidenció que

5 Como la enseñanza de la lógica en manos de profesores de español, lo cual invita a pensar que existe una intención de confundir o evitar la enseñanza correcta, en este caso, de la lógica. 
se hicieron desde ideologías acordes a la política (neoliberalista) de ramo -como lo plantea Barboza (2012) en su artículo Proyecto ¿Ética, estética y ciudadanía?”... y ... ¿del MEP?-. Por lo que ante un nuevo gobierno y un nuevo mando en el MEP, más que tener esperanzas ingenuas lo que parece más acertado es seguir vigilantes para que cada día se mantenga en el país una política justa, ética y transparente, así como una educación cada vez más crítica.

\section{CONCLUSIÓN}

Ninguna forma de gobierno es perfecta, pero Costa Rica es un país que cuenta con la estructura y la capacidad para ser una nación cada vez mejor organizada y dirigida. Desgraciadamente, la corrupción política, cáncer de muchos países, no ha permitido alcanzar el mejor gobierno de este país, pero esto no solo es culpa de los gobernantes, también los gobernados tienen su cuota de culpabilidad.

La idea de Sócrates, expuesta por Platón (1988), de que los gobernantes deben ser personas preparadas en política y estos deben ser elegidos por ciudadanos racionales, sigue siendo vigente y válida en el contexto actual, pero esto es muy difícil de lograr cuando la situación política de un país se ha corrompido y, por ende, ha corrompido la educación y demás aspectos sociales.

Además, como se observó durante este artículo, fenómenos políticos internacionales, como es el caso de la posverdad, han afectado a Costa Rica. Esto se pudo evidenciar, principalmente, por medio de la propaganda política del partido Restauración Nacional para intentar llegar al mando del poder ejecutivo y aunque no logran este cometido, en el plano legislativo dan un fuerte golpe a la racionalidad del pueblo al obtener catorce diputados de los cuales, como se ha podido observar en los periódicos, algunos no cuentan con ninguna preparación en política, ni educación superior (Soto, 2018); la mitad son pastores evangélicos que defienden su fe por encima de los Derechos Humanos (Miranda, 2018) o, siendo periodistas algunos, no brindan declaraciones a la prensa (Sequeira, 2018).

La responsabilidad de los académicos, científicos, distintos profesionales e, idealmente, de cualquier ciudadano no necesariamente con estudios superiores, es siempre informarse sobre la manera en cómo se está 
gobernando el país para determinar (ya sea a través de opiniones críticas, como la aquí realizada, u otras formas de expresión) si el proceder de los políticos está o no en beneficio de todos. Esto, aunado al hecho de apelar por una mejor y más formación crítica de los ciudadanos desde tempranas edades, puede que represente un mejor gobierno y una mejor democracia en la que todos aportan y ejercen el voto de manera responsable y racional.

Por lo tanto, antes de volver a tener unas elecciones más desalentadoras para la democracia y la racionalidad del pueblo costarricense -que se fundamenta en el humanismo y el racionalismo según su anterior (1994) y actual Política Educativa (2016)-, es necesario, además de realizar análisis críticos de la política, también vigilar que la educación, así como se establece en la nueva Política Educativa, sea cada vez más crítica, más cívicamente activa y esté orientada hacia el bien de toda la sociedad (siguiendo los postulados de la Declaración Universal de los Derechos Humanos) y no solamente hacia una parte de esta como lo pretendió y lo pretende hacer el partido de Restauración Nacional en Costa Rica.

\section{REFERENCIAS}

Barboza, G. (23 de mayo de 2012). Proyecto "¿Ética, estética y ciudadanía?"... y... ¿del MEP? Semanario universidad. Recuperado de http://semanariouniversidad.ucr.cr/opinion/ proyecto-tica-esttica-y-ciudadana-y-del-mep/

Cambronero, N. (02 de octubre de 2009). Juicio Caja-Fischel llega a su fin. La República. Recuperado de https://www.larepublica.net/noticia/ juicio_cajafischel_llega_a_su_fin

Constitución Política de la República de Costa Rica. (1949). Recuperado de http://www.pgrweb.go.cr/scij/busqueda/normativa/normas/nrm_texto_completo. aspx?param1=NRTC\&nValor1=1\&nValor2=871\&strTipM=TC

Convención Americana sobre Derechos Humanos. (1969). Recuperado de https://www.dipublico.org/3519/convencion-americana-sobre-derechos-humanos-\%E2\%80\%93-pacto-de-san-jose-de-costa-rica/ 
Cuevas, R. (3 de octubre de 2017). Costa Rica: Corrupción en los tres poderes de la República. Nodal. Recuperado de https://www.nodal. am/2017/10/costa-rica-corrupcion-los-tres-poderes-la-republica-rafael-cuevas-molina/

Jiménez, I. (2 de febrero de 2017). Las nuevas audiencias en su laberinto de la posverdad. Forbes México. Recuperado de https://www.forbes. com.mx/las-nuevas-audiencias-laberinto-la-posverdad/

Keyes, R. (2004). The Post-Truth Era: Dishonesty and Deception in Contemporary Life. New York: St. Martin Press.

Kopan, T. (12 de agosto de 2016). Donald Trump ahora dice que fue "sarcasmo" decir que Obama fundó ISIS. CNNespañol. Recuperado de https://cnnespanol.cnn.com/2016/08/12/donald-trump-ahora-diceque-fue-sarcasmo-decir-que-obama-fundo-isis/

Ley 9379. Ley Para la promoción de la autonomía personal de las personas con discapacidad. Diario Oficial La Gaceta n. 166 San José, Costa Rica, 30 de agosto de 2016.

Madrigal, R. (28 de febrero de 2018). Fabricio Alvarado dice que salirse de la Corte de Derechos Humanos ya 'no va a ser necesario'. La Nación. Recuperado de https://www.nacion.com/el-pais/ politica/salirse-de-la-convencion-de-derechos-humanos-no/ VQGG3RUCSFBVZGXDDBX54XUQRA/story/

McKirdy, E. (11 de agosto de 2016). Donald Trump dice que Obama es el "fundador de ISIS". CNNespañol. Recuperado de https://cnnespanol.cnn.com/2016/08/11/ donald-trump-dice-que-obama-es-el-fundador-de-isis/

Ministerio de Educación Pública de Costa Rica. (1994). Política Educativa hacia el Siglo XXI. Recuperado de http://www.mep.go.cr/ politica-educativa

Ministerio de Educación Pública de Costa Rica. (2009a). Programa Ética, estética y ciudadanía. Recuperado de http://www.mep.go.cr/ programas-y-proyectos/programa-etica-estetica-y-ciudadania 
Ministerio de Educación Pública de Costa Rica. (2009b). Programa de Estudio de Educación Cívica. Recuperado de http://www.mep.go.cr/ sites/default/files/programadeestudio/programas/civica3ciclo_diversificada.pdf

Ministerio de Educación Pública de Costa Rica. (2009c). Programa de Estudio de Español para el III Ciclo y Educación Diversificada. Recuperado de http://www.drea.co.cr/espanol/programas-de-estudio-de-espa\%C3\%B1ol-tercer-ciclo-y-educaci\%C3\%B3n-diversificada

Ministerio de Educación Pública de Costa Rica. (2013). Programa de Estudio de Estudios sociales y Educación Cívica para el I y I/ Ciclos de la Educación General Básica. Recuperado de http://www.mep. go.cr/sites/default/files/programadeestudio/programas/esocialesecivica1y2ciclo.pdf

Ministerio de Educación Pública de Costa Rica. (2016). Política Educativa. Recuperado de http://www.mep.go.cr/politica-educativa

Miranda, H. (6 de febrero de 2018). Mitad de diputados de Restauración Nacional son pastores evangélicos. Semanario Universidad. Recuperado de https://semanariouniversidad.com/pais/ mitad-diputados-restauracion-nacional-pastores-evangelicos/

Muñoz, I. (1977). Actitud de Sócrates ante la democracia ateniense. Revista de Estudios políticos, (211), 39-60.

Nun, J. (28 de febrero de 2017). La posverdad marca el fin de una época. La Nación. Recuperado de https://www.lanacion.com. ar/1988503-la-posverdad-marca-el-fin-de-una-epoca

Nuñez, S. (1 de mayo de 2011). Imponen 5 años de cárcel a expresidente Rodríguez. La Prensa Libre. Recuperado de https://web. archive.org/web/20110501012528/http://www.prensalibre.cr/pl/ nacional/42652-ex-presidente-miguel-angel-rodriguez-condenado-a-cinco-anos-de-prision-.html

Oxford Dictionaries Online. (2019). Recuperado de https://en.oxforddictionaries.com/definition/post-truth 
Platón. (1988). La República. Madrid: Alianza Editorial.

Ramoneda, J. (2003). Las otras caras del civismo. Barcelona. Metrópolis Mediterránea. B54. Recuperado de http://www.bcn.cat/publicacions/ bmm/54/cs_opinio.htm

Romero, F. (11 de enero de 2018). Fabricio Alvarado dispuesto a salirse de la Corte IDH para que no le 'impongan' agenda LGTBI. El mundo.cr. Recuperado de https://www.elmundo.cr/fabricio-alvarado-dispuesto-salirse-la-corte-idh-no-le-impongan-agenda-lgtbi/

Sancho, M. (26 de agosto de 2017). Este es el caso del cemento chino que tiene pendiente al país. Crhoy.com. Recuperado de https://www.crhoy.com/nacionales/ este-es-el-caso-del-cemento-chino-que-tiene-pendiente-al-pais/

Sans, A., Jenkins, M., y Elizondo, G. (2009). Programa de Ética, Estética y Ciudadanía. Informe de Evaluación Fase I. PNUD. Recuperado de https://erc.undp.org/evaluation/documents/download/3629

Sequeira, A. (6 de febrero de 2018). Cúpula de Restauración ordena a diputados electos no dar declaraciones a medios. La Nación. Recuperado de https://www.nacion.com/el-pais/politica/cupula-de-restauracion-ordena-a-diputados-electos/JM5UYX6R65AKLKJXDAGQAOWAD4/ storyl

Soler, D. (24 de junio de 2016). Farage admite que la campaña del «Leave» mintió sobre el dinero que pagan a la Unión Europea. $A B C$. Recuperado de https://www.abc.es/internacional/abci-farage-admite-campana-leave-mintio-sobre-dinero-pagan-union-europea-201606241339_noticia.html

Soto, J. (6 febrero, 2018). Diputada de Fabricio Alvarado luchará por el “Magisterio de la Familia". Crhoy.com. Recuperado de https://www.crhoy. $\mathrm{com} /$ nacionales/diputada-de-fabricio-alvarado-luchara-por-el-magisterio-de-la-familia/ 
